\title{
LAS ENFERMEDADES VENÉREAS Y LA REGULACIÓN DE LA SEXUALIDAD EN \\ LA ESPAÑA CONTEMPORÁNEA
}

\author{
Ramón Castejón Bolea \\ Depto. de Salud Pública, Historia de la Ciencia y Ginecología, \\ Facultad de Medicina, Universidad Miguel Hernández
}

\section{RESUMEN}

Se estudian las respuestas médicas generadas a finales del siglo XIX y primer tercio del siglo $\mathrm{XX}$ en relación con el problema venéreo en tanto regularon y definieron conductas y roles sexuales, analizando los discursos y las prácticas de los médicos sobre las enfermedades venéreas. Se exploran las legislaciones antivenéreas, las variaciones del modelo epidemiológico y las estrategias preventivas.

PALABRAS CLAVE: Salud pública, epidemiología, sexualidad, enfermedades venéreas, España, siglos XIX y XX.

\section{SUMMARY}

This article studies the medical answers during the late 19th century and the first third of the $20^{\text {th }}$ century in relation to the venereal problem. It attempts to disclose the way these answers regulated and defined sexual behaviour and roles by analyzing the discourses and practices of doctors dealing with venereal diseases. It will explore antivenereal legislations, variations in the epidemiological model and preventive strategies.

KEY WORDS: Public health, epidemiology, sexuality, venereal diseases, Spain, $19^{\text {th }}$ and $20^{\text {th }}$ centuries

\section{INTRODUCCIÓN}

La consideración de que las respuestas de la sociedad a las enfermedades venéreas han sido uno de los ejes centrales de la red de discursos que han construido y regulado la sexualidad en la sociedad moderna ha generado, desde los primeros trabajos de Foucault, una rica producción de investigacio- 
nes ${ }^{1}$. Para la historiografía médica, como ha señalado Bertrand Taithe, «la historia de las enfermedades venéreas ha contribuido a configurar de manera duradera el marco intelectual de la historia de la medicina», ejerciendo «una permanente fascinación como enfermedades en la historia y como enfermedades con una historia» ${ }^{2}$.

El significado de las enfermedades venéreas para reflejar y compartir percepciones de la sexualidad y la respuesta del estado a los modelos de conducta sexual ha sido objeto de investigación en los diferentes trabajos realizados en los últimos años sobre la prostitución y la sexualidad en la España contemporánea ${ }^{3}$. Sin embargo estos trabajos no se han centrado de manera específica en las enfermedades venéreas ni en las respuestas médicas a estas enfermedades ${ }^{4}$.

1 Véase, Davidson, R. (1994), «Venereal Disease, Sexual Morality, and Public Health in Interwar Scotland», Journal of the History of Sexuality, 5, 267-294.

2 Thaite, B. (2001), «Morality is not a Curable Disease: Probing the History of Venereal Diseases, Morality and Prostitution», Social History of Medicine, 14, 337-350, pp. 337-339.

3 GuEREÑA, J.-L. (1994), «La réglementation de la prostitution en Espagne aux XIX ${ }^{\mathrm{e}}-\mathrm{XX}^{\mathrm{e}}$ siècles», en: CARRASCO, R. (ed.), La prostitution en Espagne de l'époque des Rois Catholiques à la II République, París, Les Belles Lettres [Annales Littéraires de l'Université de Besançon], 229-257; GUEREÑA, J.-L. (1995), «Los orígenes de la reglamentación en la España contemporánea. De la propuesta de Cabarrús (1792) al Reglamento de Madrid (1847), Dynamis, 15, 401441; CASTEJÓN BOLEA, R. (2001), Moral sexual y enfermedad: la medicina española frente al peligro venéreo (1868-1936), Granada, Universidad de Granada. Para una revisión sobre la situación historiográfica en torno a la prostitución, véase, GUEREÑA, J.-L. (1997), «De historia prostitutionis. La prostitución en la España contemporánea», Ayer, 25, 35-72. Ese mismo año se publicó un monográfico sobre la prostitución en la España contemporánea, «Prostitución y sociedad en España. Siglos XIX y XX», Bulletin d'Histoire Contemporaine de l'Espagne, 25, 1997. También GUEREÑA, J.-L. (1999), «La policía sanitaria de las mujeres públicas (Zaragoza, 1845). Los orígenes del reglamentarismo en la España contemporánea», Revista de Historia Jerónimo Zurita, 74, 7-25. Sobre la historia de la sexualidad en España destacar los trabajos de VAZQUEZ, F. (1996), «Historia de la sexualidad en España: problemas metodológicos y estado de la cuestión», Hispania, LVI/3, 1007-1035 y VÁZQUEZ, F.; MoRENO, A. (1997), Sexo y razón. Una genealogía de la moral sexual en España (Siglos XVI-XX), Madrid, Akal.

4 Sobre el significado de las enfermedades venéreas y las respuestas sociales y médicas generadas en el siglo XIX y XX, véase especialmente: BRANDT, A.M. (1987), No Magic Bullet. A Social History of Venereal Disease in the United States since 1880, Oxford, Oxford University Press; CASSEL, J. (1987), The secret plague. Venereal Disease in Canada, 18381939, Toronto, University of Toronto Press; QueTEL, C. (1990), History of Syphilis, Cambridge, Polity Press; EVANS, D. (1992), «Tackling the 'Hideous Scourge': The Creation of the Venereal Disease Centres in Early Twentieth-Century Britain», Social History of Medicine, 5, 413-433; DAVIDSON, R. (1997), «Venereal Disease, Public Health and Social Control: 
Utilizando como materiales los discursos que los médicos y los higienistas elaboraron sobre las enfermedades venéreas, así como sus realizaciones prácticas tanto desde la perspectiva de la salud pública como desde la especialidad de dermato-venereología, este trabajo pretende acercarse a las respuestas médicas generadas en torno al problema venéreo en tanto regularon y definieron la sexualidad y los roles sexuales, centrándose en las diferentes legislaciones antivenéreas, en las variaciones en el modelo epidemiológico que sustentaba las intervenciones médicas y en las estrategias preventivas desarrolladas para enfrentar el «peligro venéreo».

\section{El MARCO REGLAMENTARISTA Y LAS LEGISLACIONES ANTIVENÉREAS}

Una de las principales claves de las políticas antivenéreas en la España contemporánea es la existencia de un sistema de reglamentación de la prostitución que se prolonga a lo largo de buena parte del siglo XIX y del siglo XX.

La creciente preocupación que desde finales del siglo XVIII se detecta en muchas naciones europeas por las enfermedades venéreas se enmarcaba en el contexto del interés de las naciones por la salud de sus poblaciones, por la salud de sus jóvenes y de sus ejércitos ${ }^{5}$. A estas preocupaciones no eran ajenas la presión por parte de las autoridades militares que abogaban por controlar sanitariamente a las prostitutas mediante la reglamentación. En España, conforme discurría el último tercio del siglo XIX, el discurso médico-higienista sobre la morbi-mortalidad de los infectados y sus consecuencias económicas y demográficas (con especial énfasis sobre las «generaciones venideras») fue adquiriendo tonos más dramáticos y alarmistas. Las cifras de incidencia y prevalencia de las enfermedades venéreas iban en aumento, aunque su fiabilidad fuera escasa y en casi todos los casos se utilizaran fuentes de otros países dada la inexistencia en el nuestro de registros fiables hasta ya entrado el siglo XX. Así, un higienista consideraba en 1886 que «... la sífilis causaba por sí sola más estragos que todas las enfermedades contagiosa juntas» ${ }^{6}$. Este discurso de los

The Scottish Experience in a Comparative Perspective», Dynamis, 17, 341-368 y HALL, L. y DAVIDSON, R. (ed). (2001), Sex, Sin and Suffering. Venereal disease and European society since 1870, London \& New York, Routledge.

5 Bullough, V.; Bullough, B. (1987), Women and prostitution. A Social History, Buffalo, Prometheus Books, 1987, pp. 192-196.

6 Gelabert, E. (1886), De la prostitución, en sus relaciones con la Higiene, en el doble concepto de la profilaxis de la sifilis y de la reglamentación. Discurso leido en la sesión inaugu- 
médicos-higienistas incluía otras preocupaciones y ansiedades sociales. Las informaciones recogidas por la Comisión de Reformas Sociales en su respuesta a la pregunta 97 del cuestionario y publicadas en 1889 coincidían en denunciar, como pernicioso para la moralidad de la mujer, el trabajo en fábricas y talleres. Igualmente, el concubinato aparecía investigado en la pregunta 57 de la Comisión y los datos resultantes mostraban la gravedad de esta desviación respecto a la moral católica, dominante en la sociedad española. Ante esta situación, la Santa Sede pidió al nuncio que hiciera un amplio informe sobre concubinatos ${ }^{7}$. La extensión de las enfermedades venéreas se convirtió, pues, en un indicador de la ruptura de la norma sexual, de los ataques que sufría la familia y el matrimonio: «Y no es solo la medicina la que está demandando la pronta desaparición de las enfermedades sifilíticas: lo exige también la moral, guardadora de la paz de las familias $\rangle^{8}$. Estas preocupaciones alentaron el programa moral como parte de las estrategias antivenéreas.

La mayoría de los higienistas españoles, imbuidos de su vocación intervencionista, sustentaron la estrategia reglamentarista como la más adecuada para hacer frente al creciente problema de las enfermedades venéreas. Basados en el modelo epidemiológico que consideraba a la prostitución como el reservorio de la enfermedad basaron sus intervenciones en el control médico de la prostitución. Esta identificación de las enfermedades venéreas con la prostitución ha sido considerada por el historiador Bertrand Taithe como «retórica moralista aplicada a la epidemiología»?.

Además, la creciente industrialización y urbanización acontecida en España a lo largo de la segunda mitad del siglo XIX, alentaba la percepción de que la prostitución y su correlato de enfermedades venéreas se extendían por la nación lo que les llevó a situar estos problemas dentro de la «cuestión social» y proponer medidas de control y moralización de las clases trabajadoras ${ }^{10}$.

ral . en 14 de enero de 1886 ...Academia y Laboratorio de Ciencias Médicas de Cataluña, Barcelona, Est. Tip. de los Sucesores de N. Ramírez y C., p. 26.

7 RoBles MuÑOZ, C. (1986), «Algunos aspectos del sistema moral de la sociedad española después de la Revolución de 1868», Revista Internacional de Sociología, 44, 579-607.

8 PRATS Bosch, A. (1861), La prostitución y la sifilis, Barcelona, Luis Tasso, p. 9.

9 TAITHE (2001), p. 350.

10 Sobre las relaciones entre Higiene y Moral en España véase: RODRIGUEZ OCAÑA, E. (1992), «Paz, trabajo, higiene. Los enunciados acerca de la higiene industrial en la España del siglo XIX», en: HUERTAS, R. y CAMPOS MARÍN, R., Medicina social y clase obrera en España (siglos XIX y XX), Madrid, Fundación de Investigaciones Marxistas, p. 385 y CAMPOS MARÍn, R. (1995), «La sociedad enferma: Higiene y Moral en España en la segunda mitad del siglo XIX y principios del XX», Hispania, LV/3, 1093-1112. 
En la práctica el modelo reglamentarista español tomó como referente a su homónimo francés, promocionado desde la Restauración y desarrollado bajo el esquema diseñado por el Dr. Alexandre Parent Duchatelet. En España, el modelo se mantendrá vigente exceptuando el periodo abierto 1935-1941, hasta que el régimen franquista suprimió oficialmente las «casas toleradas» en 1956.

Desde los primeros reglamentos, el de Zaragoza de 1845 y el de Madrid de $1847^{11}$, el problema de la prostitución es abordado desde una perspectiva de orden público y sanitaria basada en la inscripción de las prostitutas en un registro, su inspección médica obligatoria con una periodicidad que variaba según los reglamentos y la hospitalización forzosa en caso de enfermedad contagiosa. El modelo reglamentarista fue extendiéndose por todo el territorio español mediante iniciativas de los gobiernos civiles y de los ayuntamientos. En general el dispositivo reglamentarista dependía de los gobiernos civiles si exceptuamos el periodo entre 1889 y 1892 en que dependió de los ayuntamientos.

La prostituta, pues, se convertía en objeto de vigilancia e intervención por parte de policías y médicos. Considerada como el reservorio de la enfermedad venérea, la discriminación legal que suponían los reglamentos era justificada por un higienista encargado de los reconocimientos médicos porque «... presentándose al descubierto y sin restricción, ofende la moralidad y el pudor público, ataca a la conciencia por el mal ejemplo, infringe la ley del trabajo, que no solo alcanza al hombre sino también a la mujer, y compromete la salud pública propagando enfermedades contagiosas» $\rangle^{12}$. La asociación entre prostituta y enfermedad venérea quedaba manifiesta, por ejemplo, en un proyecto de reglamentación publicado en 1882 donde se consideraba circunstancia decisiva, para que una prostituta «clandestina» detenida fuera inscrita a la fuerza, el haber padecido enfermedad venérea ${ }^{13}$.

11 GuEREÑA (1995), pp. 401-441. A estos siguen, sin ánimo de ser exhaustivos, los de Jerez (1855), Sevilla (1859), Alicante (1860), Santander (1862), Cádiz (1864), Valencia (1865), Barcelona (1867), Bilbao (1873), Zamora (1873), San Sebastián (1876), Ávila (1881), La Coruña (1884), Granada (1884), Almería (1885), Málaga (1885), Lérida (1886), Albacete (1889), Burgos (1889), Murcia (1889), Pamplona (1889), Vigo (1889); GuEREÑA, (1994), pp. 307-314.

12 Miguel y Viguri, I. (1877), Medidas de policía médica en relación con la sifilis. Discurso leído en la Academia Médico Quirúrgica española, Madrid, Imp. De Enrique Teodoro, p. 46.

13 Sereñana Partagás, P. (1882), La prostitución en la ciudad de Barcelona, estudiada como enfermedad social y considerada como origen de otras enfermedades dinámicas, orgánicas y morales de la población barcelonesa, Barcelona, Imp. de los Sucesores de Ramírez y Cía, p. 232. Esta obra se encuentra disponible en Internet a texto completo en la Colección Geo-Crítica, textos electrónicos, $\mathrm{n}^{\circ}$ 2, diciembre 2000, Universidad de Barcelona, WWW. ub.es/geocrit/pspoprt.htm. 
Por otra parte, el discurso abolicionista — con su protesta contra la discriminación de los reglamentos, de aplicación exclusiva a la mujer - no penetró apenas en el siglo XIX entre los médicos, y su repercusión fue también escasa en otros medios, incluidas las esferas políticas. No sería hasta los años 20 del siglo XX, con la fundación en Madrid en 1922, por los médicos HernándezSampelayo y César Juarros, de la Sociedad Española de Abolicionismo, así como con la propagación de la doctrina abolicionista entre sindicatos y partidos de izquierda y el peso creciente de las organizaciones feministas, cuando comience a producirse en nuestro país la difusión masiva del credo que defendía el desmantelamiento del dispositivo reglamentarista ${ }^{14}$.

Terminando la segunda década del siglo XX, las Bases para la reglamentación de la profilaxis pública de las enfermedades venéreo-sifiliticas, publicadas en 1918, marcan una inflexión en las estrategias de lucha antivenérea. Constituyen el marco legal en la que ésta se va a desarrollar hasta los años 30 y pueden ser definidas como neorreglamentaristas, con un marcado control de todo el dispositivo por parte de los médicos higienistas, los inspectores provinciales y municipales de sanidad, y los clínicos venereólogos. Aunque los aspectos policiales y de vigilancia estarán presentes en estas Bases, hay una voluntad explícita de centrarse en los aspectos sanitarios de la prostitución.

Desde el punto de vista asistencial, la legislación de 1918 ofreció el marco legal para el desarrollo del programa de dispensarios antivenéreos accesibles y gratuitos. Sin embargo, este programa al igual que el resto de proyectos sanitarios se encontraba limitado por la dimensión económica de los mismos.

A finales de los años de la década de 1920, la educación y la prevención individual como estrategias antivenéreas ocuparon un lugar central en el debate sobre las políticas antivenéreas. Al desarrollo del programa asistencial había que añadir la difusión de medios de profilaxis individual, los medios de propaganda antivenérea y la educación sexual antivenérea. El Comité Ejecutivo Antivenéreo declaraba en 1928: «Bien claramente hemos procurado decir que la extinción de la sífilis no es sólo un problema de ciencia, sino también de cultura [...] A la profilaxis por el tratamiento debe acompañar el empleo de la propaganda sanitaria por todo género de medios, consejos, cine, carteles, conferencias de radiotelefonía, folletos, dibujos, etc» ${ }^{15}$.

Finalmente, cuando las recomendaciones morales y las estrategias educativas no daban los frutos esperados, siendo su eficacia cuestionada, y además las víc-

14 VazQuez García; Moreno Mengibar (1997), pp. 88-100.

15 Comité EJECutivo ANTIVEnÉreo (1928), Algo de su labor en la lucha contra las enfermedades venéreas. Dispensarios y Sifilicomios, Madrid, Imp. Clásica Española, pp. 8-9. 
timas inocentes no quedaban protegidas, la mayoría de dermato-venereólogos e higienistas apoyaron las estrategias coercitivas mediante el reconocimiento y el tratamiento obligatorios, así como el delito de contagio venéreo ${ }^{16}$.

Las Bases para la reorganización de la profilaxis pública de las enfermedades venéreosifiliticas, aprobadas por R.O. de 27 de mayo de 1930, durante el gobierno intermedio de Berenguer a la caída de la Dictadura, fueron el marco legislativo para la aplicación de las medidas coercitivas. Estas Bases establecían la obligatoriedad del tratamiento, bien de manera privada o en un establecimiento público, a toda persona afecta de enfermedad venérea. Los padres o tutores de los menores quedaban obligados a asegurar el tratamiento de éstos. Los médicos debían comunicar a los enfermos en periodo de contagio que si éstos abandonaban al tratamiento, lo pondrían en conocimiento de las autoridades sanitarias a menos que tuvieran constancia de que, en un plazo de cuarenta y ocho horas, lo continuaban con otro facultativo. Aquellos enfermos contagiosos que no se sometieran a tratamiento con regularidad o aquellos cuyo tratamiento extrahospitalario durante la fase de máxima contagiosidad constituyera un peligro social podrían ser hospitalizados forzosamente por las autoridades sanitarias. Aquellos enfermos que no cumplieran con el tratamiento forzoso podrían ser obligados a reconocerse por un médico de la «Lucha Oficial Antivenérea», y en su caso a la hospitalización forzosa. Todos los enfermos venéreos quedaban obligados, si el caso lo requería, a un examen médico periódico.

No recogían, sin embargo, estas Bases la declaración obligatoria de enfermedad sino que el médico debía informarse de las fuentes de contagio y transmitir a las autoridades sanitarias la información que el paciente le quisiera comunicar, lo que se denominaba «declaración condicional». Estas estrategias coercitivas respondían a la presión ejercida por los higienistas o médicos sociales y los clínicos venereólogos:

«El Estado tiene el deber de dar facilidades para el tratamiento, y debe por lo tanto exigir mediante leyes apropiadas, que todo ciudadano enfermo, hombre o mujer, deje de ser lo antes posible peligroso para la sociedad, mediante un tratamiento apropiado. De estas medidas legales como es natural estará libre todo aquel que tenga conciencia de su responsabilidad; por el contrario serán aplicables a todo

16 Sobre la figura del delito de contagio venéreo, véase, CASTEJON BOLEA, R. (1997), «El delito de contagio venéreo: la penalización como instrumento jurídico de la lucha antivenérea», en: MONTIEL, L.; PORRAS, I., De la responsabilidad individual a la culpabilización de la víctima, Aranjuez, Doce Calles, pp. 203-218. 
el que no se preocupe de su enfermedad y quede encargado de propagarla; a éstos es necesario tratarlos y llegar, si es preciso, hasta la hospitalización forzosa» ${ }^{17}$.

Esta asunción mayoritaria de las estrategias coercitivas por parte de los higienistas y clínicos venereólogos significaba la aceptación implícita de que el reglamentarismo no había sido capaz de contener la incidencia de las enfermedades venéreas, con lo que el modelo entraba en crisis y se abrían las puertas al abolicionismo. Existen pruebas de que al menos tres razones indujeron la crisis. La primera, el reglamentarismo no era capaz de controlar a las prostitutas «clandestinas», principal fuente de contagio en la construcción epidemiológica de muchos higienistas y venereólogos:

«No está en nuestro propósito hacer aquí una crítica [...], de la reglamentación; pero es necesario decir, para que sirva de norte, que el temor a los reglamentos, a la hospitalización forzosa y a la policía, es en la gran ciudad un incremento de la prostitución clandestina y aleja a muchas mujeres sospechosas o declaradamente enfermas, del trato asiduo con las instituciones sanitarias» ${ }^{18}$.

Además, desde la segunda década del siglo se estaba generalizando la idea de que la reglamentación, como estaba siendo aplicada, no estaba respondiendo a lo que se percibía como nuevas formas de difusión de la enfermedad desde la prostitución clandestina hacia las clases medias:

«Con la prostitución reglamentada tal como está hoy[...] no podremos evitar la contaminación del mal en el estudiante [...], en el militar [...], en el dependiente [...], en el casado [...], en el comerciante [...], y jamás llegaremos á evitar la contaminación del banquero, del hombre de negocios, del bolsista, del jurisconsulto, del general, del acaudalado comerciante, del político, del pintor, del médico, [...]» ${ }^{19}$.

A estas dos razones se añadía la demostrada ineficacia del sistema reglamentarista, desde el punto de vista del «valor médico» de los reconocimientos, para

17 Gregorio Garcia-Serrano, E. (1930), Profilaxis médico-social de la sifilis. Discurso leido en la Real Academia de Medicina de Zaragoza en la recepción pública del Dr..., Zaragoza, Industrias Gráficas Alfredo Uriarte, p. 55.

18 Fernandez de la Portilla, J. (1934), La lucha antivenérea en España (Diez años de experiencia), Madrid, Gráfica Universal, p. 37.

19 Portillo, L. del (1919), Tratado práctico de Venereología y Sifiliografía, Madrid, Imp. Juan Pueyo, tomo I, p. 227. «Por otra parte, los reglamentos no actúan más que sobre las meretrices callejeras o pobres, y dejan en absoluta libertad a las hetairas distinguidas [...]. FERNÁNDEZ DE LA PORTILLA (1934), pp. 37 y 46. 
detectar a las prostitutas capaces de transmitir las enfermedades venéreas ${ }^{20}$. Para principios de la década de los 30 , el modelo reglamentarista había entrado, pues, en crisis y tenía sus días contados. En 1932, se frustra un proyecto de Ley abolicionista en el que participaron destacados venereólogos y el prestigioso jurista Luis Jiménez de Asúa. El proyecto generó debates en el seno del Consejo Nacional de Sanidad en torno al tratamiento obligatorio y a la declaración obligatoria de enfermedad.

La presión sobre el reglamentarismo seguía aumentando. En mayo de 1932, las abolicionistas de Madrid, con el apoyo del psiquiatra César Juarros, dedicaban una semana a la propaganda de sus ideas ante la lentitud del Ministerio de la Gobernación para decretar la abolición del reglamentarismo. La mayoría de los médicos de la Lucha Oficial Antivenérea, al menos en Madrid y las grandes ciudades, se mostraban abiertamente abolicionistas ${ }^{21}$. El 28 de junio de 1935 vio la luz el decreto que suprimía la reglamentación en España, cerrando un periodo que se había iniciado a mediados del siglo XIX. Este nuevo marco legislativo mantenía la posibilidad de reconocimiento médico periódico cuando las autoridades sanitarias lo consideraran y la hospitalización forzosa si era necesario ${ }^{22}$.

\section{EL MODELO EPIDEMIOLÓGICO Y LAS ESTRATEGIAS COERCITIVAS}

A pesar de la existencia de posiciones diferentes a lo largo del último tercio del siglo XIX frente al problema de la prostitución, lo que era lugar común en todos los higienistas era la construcción epidemiológica que situaba el foco de las enfermedades venéreas en la prostitución, en las prostitutas: "Todos o en su mayor parte están de conformes en que el verdadero germen y criadero de la sífilis reside en la prostitución ${ }^{23}$. Esta idea que enlazaba las enfermedades venéreas a la prostitución y por tanto planteaba las respuestas médicas a estas enfermedades ligadas al control policial y sanitario de las prostitutas perma-

20 Fernandez de la Portilla (1934), pp. 37-38.

21 Ibid., p. 49.

22 «No sería ocioso, sin embargo, recabar la ayuda de la ley para investigar las fuentes de contagio que abran el camino, sin distinción de sexos ni categorías, al tratamiento, incluso forzoso, cuando de grado y por convencimiento no se logre poderlo realizar». Ibid., p. 57.

23 Roselló y Olive, R. (1883), "La sífilis y la prostitución; sus relaciones; medios de prevenir sus perniciosos efectos», en: Actas de la sesión inaugural que la Real Academia de Medicina y Cirugía de Barcelona celebró en 30 de enero de 1883, Barcelona, Imprenta de Jaime Jepús, p. 48. 
necerá vigente con el cambio de siglo y se adentrará durante el primer tercio del siglo XX. Como exponía el jefe de policía de la Sección de Higiene en Madrid en 1900:

«El contagio inmoral de la prostitución, y el contagio infectante de las enfermedades venéreas, son dos fenómenos patológicos correlativos que exigen medidas comunes de preservación y saneamiento. No es posible desligar la profilaxis médica de la profilaxis social. El vehículo humano de las enfermedades venéreas es la prostitución, y el verdadero peligro de esta dolencia moral, radica en la progresión de estas enfermedades» ${ }^{24}$.

Las preocupaciones sobre el orden moral y sexual alentaban, pues, el programa moral como parte de las estrategias médicas y entroncaban el discurso moral de la lucha antivenérea con el discurso moral de la salud pública ${ }^{25}$. La asociación entre la salud de la nación con la disciplina sexual o con la sexualidad normalizada por la religión católica, consistente con la ideología médico-moral de la higiene pública, hacía que los médicos higienistas y dermatovenereólogos vieran a las enfermedades venéreas no sólo como una patología física sino como el estigma de la transgresión de la norma sexual:

«Este afecto, que en la nosología social se denomina «prostitución», es de carácter maligno, por entrañar en sí el germen de enfermedades que, como el venéreo y la sífilis en el orden material y el libertinaje más desenfrenado en el orden moral, propenden a desgastar las fuerzas físicas e intelectuales del individuo, turban la armonía de las familias, relajan los vínculos de la amistad, aflojan los lazos del amor y destruyen los cimientos de toda sociedad civilizada» ${ }^{26}$.

Sin embargo, el modelo epidemiológico en el que se basaba el reglamentarismo iba a incluir progresivamente otros vectores para explicar la difusión de la enfermedad. La existencia de los hombres casados infectados y de la prostitución clandestina iba a explicar la incapacidad para resolver el «problema venéreo», es decir para disminuir las tasas de infectados. La higiene pública suscribía entonces una etiología que incorporaba una taxonomía explícita de culpa y pecado, diferenciando claramente entre pacientes de acuerdo a la culpabilidad moral de su condición ${ }^{27}$. A un lado del espectro, los pacientes ino-

24 Eslava, R.G. (1900), La prostitución en Madrid: apuntes para un estudio sociológico, Madrid, Vicente Rico, p. 190.

25 CAMPOS MARIN (1995).

26 SEREÑANA Y PARTAGAS (1882), p. 159.

27 DAVIDSON (1994), p. 271. 
centes, mujeres casadas y niños; en el otro lado del espectro, los pacientes culpables, hombres casados infectados y las mujeres prostitutas, reglamentadas o clandestinas:

«[...] que las enfermedades venéreas, y ya hemos dicho que entre ellas es la sífilis la más caracterizada, no se contraen exclusivamente por el mecanismo más conocido, y que pudiera hacerlas más repugnantes, sino que modalidad, al fin, de enfermedades infecciosas, afectan a un conjunto numeroso de seres inocentes que merecen de la colectividad social moderna, humana y justa, el mismo amparo, igual defensa, idénticos cuidados, cuando menos la misma compasión que los enfermos resultantes de otra infección cualquiera ${ }^{28}$.

En términos de la ideología médico-moral de los médicos higienistas y clínicos venereólogos, este grupo de pacientes (hombres casados infectados y prostitutas clandestinas) eran doblemente culpables. No solamente habían contraído las enfermedades venéreas voluntariamente y por medio de relaciones sexuales promiscuas e ilícitas sino que también permanecían como los vectores más importantes de la enfermedad dentro de sus propias familias y de su comunidad, por su abandono del tratamiento antes de ser curados y su negativa a modificar su conducta sexual. Fue esta categoría de pacientes los que dominaron el debate sobre las políticas antivenéreas y los que fundamentaron las estrategias antivenéreas coercitivas, incluyendo el reconocimiento y el tratamientos obligatorios, una vez que el modelo epidemiológico en el que se basaba el reglamentarismo se demostró ineficaz para reducir las tasas de infectados y era objeto de críticas por su discriminación hacia la mujer:

«Y contra la prostitución clandestina nos vemos a menudo desarmados. Los medios de que disponemos son de dos clases: o bien podemos tratar, por medidas sociales, de disminuir la frecuencia, o bien empleamos medidas coercitivas. En lo que se refiere al primer método, la verdad que gran número de mujeres, mejor dirigidas, cambiadas de medio, con un salario suficientemente remunerador, podrían evitar esta caída, con gran bien de la moral y de la higiene pública. Pero preciso es decir también que hay muchas en las cuales estas medidas nada podrán, y conti-

28 Fernandez de la Portilla (1934), P. 98. «Cuando la reacción Wassermann y el análisis del gonococo han demostrado [...] centenares de casos de víctimas inocentes, en que tampoco se podía poner en tela de juicio su castidad, han variado por completo las condiciones de la cuestión, y se ha planteado [...] como un problema social que afecta por igual al hombre que a la mujer, al padre que a la madre, al religioso y al seglar [...]». NAVARRO FERNANDEZ, A. (1931), Presérvate del amor impuro (enfermedades venéreas), Madrid, Agencia Española de Librería, p. 170. 
nuarán, hágase lo que se quiera, prostitutas. Contra éstas no tenemos más que las medidas coercitivas ${ }^{29}$.

Sobre estos pacientes recaía la responsabilidad de la culpa por la continua incidencia de enfermedades venéreas, a pesar de la introducción de las nuevas terapias médicas y del programa asistencial puesto en marcha desde 1918. Como ha señalado Roger Davidson, su identificación y condena por clínicos e higienistas fue un potente ejemplo de los procesos de estereotipación en la construcción social de las «sexualidades peligrosas» ${ }^{30}$.

Las jóvenes solteras infectadas eran consideradas como vectores principales de las enfermedades venéreas a través de su promiscuidad sexual y el frecuente recurso a la prostitución amateur y clandestina. Estas mujeres sustentaban el modelo epidemiológico en el que se les consideraba como el origen de la infección contaminando la masculinidad y la eficiencia de la raza. En su preocupación por las mujeres solteras infectadas los médicos estaban también perpetuando la idea de que eran las prostitutas clandestinas, con su abandono de las precauciones y/o del tratamiento efectivo, con su mayor número y su mayor morbilidad, el foco real de las enfermedades venéreas, mucho más que las prostitutas reglamentadas ${ }^{31}$.

Estas mujeres jóvenes que ya desde finales del siglo XIX eran consideradas como un reservorio importante de las enfermedades venéreas aparecían como jóvenes trabajadoras que de una manera «amateur» recurrían a la prostitución:

«También en Barcelona las prostitutas públicas clandestinas ascienden á un gran número y se dividen en dos categorías: unas que son la escoria de la prostitución inscrita, de la cual han sido arrojadas por no poder pagar la «visita médica», pues ni para comer tenían [...] La otra categoría, mucho más decente — estéticamente hablando- la componen algunas jóvenes costureras, sombrereras, corseteras, dependientes ocupadas en el despacho de perfumerías, guanterías y otros comercios, sirvientas, vendedoras de cigarrillos, libritos de fumar y periódicos, amén de las que viven exclusivamente de su cuerpo [...] estas mujeres, como es natural, no sujetas á la visita sanitaria propagan el venéreo y la sífilis de una manera espantosa ${ }^{32}$.

29 Portillo (1919), p. 64.

30 DAVIDSON (1994), p. 274.

31 Portillo (1919), p. 63. NAVARro Fernandez (1931), p. 128.

32 Sereñana y Partagas (1882), p. 146. Algunos médicos sostenían que ciertas profesiones estaban predestinadas: «Las clandestinas pertenecen a las profesiones más variadas; pero algunos oficios tienen predestinación: tales son domésticas, costureras, modistas, planchadoras, etc». PORTILLO (1919), p. 23. 
La R.O. de 1930, en la que colaboraron destacados miembros de la Academia Española de Dermatología y Sifiliografía (AEDS), suponía la ampliación a toda la población de las medidas coercitivas para asegurar el control y el tratamiento de los enfermos. Estas estrategias suponían la aceptación del hombre como «vector de contagio» entre los «reservorios» constituidos por las prostitutas, reglamentadas y sobre todo clandestinas y el resto de la sociedad, principalmente las «víctimas inocentes» (mujeres casadas y niños) $)^{33}$ :

El papel del hombre casado como transmisor de la enfermedad y responsable de su difusión en el mundo familiar (las víctimas inocentes) era puesto de manifiesto a principios del siglo XX por aquellos dermato-venereólogos más sensibles a las críticas abolicionistas ${ }^{34}$. A partir de la tercera década del siglo XX, el impacto de la promiscuidad masculina sobre la familia y la salud racial va a ir ocupando un lugar importante en las preocupaciones y en las estrategias de la lucha antivenérea.

Julio Bejarano, que había sido director general de Sanidad y ejercía como director en el dispensario Azúa de Madrid, exponía en 1935 en el I Congreso Nacional de Sanidad lo que consideraba las claves de la lucha antivenérea: I) tratamiento obligatorio; II) implantación del delito de contagio venéreo; III) declaración obligatoria o condicionada; IV) certificado o reconocimiento médico prenupcial; V) supresión de la reglamentación de la prostitución ${ }^{35}$.

Otra de las estrategias enunciadas por la legislación coercitiva de 1930 fue la del descubrimiento de las fuentes de contagio, o en términos de la epidemiología actual, la búsqueda de contactos a partir de los casos. En efecto, la base tercera denominada «Investigación de las fuentes de contagio» exponía la conveniencia de crear un cuerpo de enfermeras visitadoras como auxiliar imprescindible en la tarea de detectar los contactos y aportar información sanitaria a las mujeres.

A tal efecto, en la base cuarta se manifestaba: «El médico deberá informarse de las fuentes de contagio y transmitirá las noticias que quiera comunicarle el enfermo a las autoridades sanitarias». Por lo tanto, los médicos oficiales del servicio antivenéreo y las autoridades sanitarias, conocedores de las

33 «La sífilis y la blenorragia matrimoniales é infantiles son, puede decirse 'siempre', importadas por el marido, sea cual fuere la clase social á que pertenezca el matrimonio [...] para hacer una profilaxis buena, es preciso actuar bien sobre el elemento enfermo, varón ó hembra indistintamente». PORTILLO (1919), p. 258.

34 NAVARro FERnAdEZ (1909), p. 256.

35 BEJARANO, J. (1935), «Datos acerca de la organización de la lucha antivenérea», en: $I$ Congreso Nacional de Sanidad. Libro de Actas, tomo II, Madrid, p. 66. 
posibles fuentes de contagio, lo comunicaban a las enfermeras visitadoras. Estas enfermeras, a partir de los registros y de los datos de los clínicos, incluyeron entre sus funciones el seguimiento de contactos y probablemente el seguimiento de los pacientes que abandonaban el tratamiento. Sin embargo, como parece deducirse de la base tercera el seguimiento era específico de género. Los hombres probablemente no eran sometidos normalmente a visitas domiciliarias ni eran objeto de la misma vigilancia e investigación sociomédica. De hecho, algunos dermato-venereólogos vieron en esta estrategia de investigación de fuentes de contagio la posibilidad de mantener la vigilancia sanitaria de las prostitutas en el medio rural o en ciudades de poca entidad poblacional $^{36}$.

A pesar de la afirmación de algunas autoridades sanitarias y clínicos venereólogos de que las enfermedades venéreas debían ser tratadas como un tema puramente médico, la provisión de un sistema público de medios de diagnóstico y tratamiento no significó el fin de un programa moral o la desmitificación de las enfermedades. Por el contrario, los asuntos morales y las taxonomías continuaron moldeando la etiología, la epidemiología y el seguimiento de la enfermedad venérea. Para las autoridades sanitarias, inspiradas por la ideología de la higiene social, el tratamiento médico y la instrucción moral eran soluciones mutuamente interdependientes al peligro venéreo:

«Evidentemente la lucha antivenérea es producto de muchos factores; pero es más evidente aún, que a los médicos nos compete la parte fundamental [...] . Los médicos todos [...] deben realizar la más interesante labor en la materia, que se concreta en estas aspiraciones: divulgación moral y sanitaria, diagnóstico precoz y tratamiento oportuno y suficiente» ${ }^{37}$

ESTRATEGIAS PREVENTIVAS: «LA SALUD NO ES SÓLO TUYA: TE DEBES A LOS TUYOS, A LA SOCIEDAD Y A LA RAZA»

Como se ha señalado anteriormente, las estrategias basadas en la prevención ocuparon un lugar importante dentro de las políticas médicas antivenéreas. Se podrían estructurar en la difusión de los medios de profilaxis individual (física y química), en los medios de propaganda antivenérea y en la educación sexual antivenérea, esta última incluida en un concepto más amplio de educación en higiene sexual.

36 Fernandez de la Portilla (1934), p. 91.

37 Ibid., pp. 17-18. 
Si bien la experiencia de los ejércitos en la I Guerra Mundial alentó la idea de la eficacia de los métodos químicos en la prevención de las enfermedades venéreas y de hecho en nuestro país fueron prácticas obligatorias en el medio militar a partir de 1914 en la Armada, gozando durante la segunda década del siglo XX del apoyo y credibilidad de los médicos militares, su eficacia fue cuestionada posteriormente y los médicos no las vieron como medios útiles de prevención:

« [...] Pero en cambio, preciso considerar que la profilaxis individual por la terapéutica va pisando cada vez terreno menos firme.

Las pomadas de profilácticas tipo Metchnikoff han caído en franco desuso [...] pero tanto este método como el tratamiento general preventivo (tandas cortas de salvarsán o bismuto a los presuntos infectados), ha demostrado en la práctica que muchas veces no consiguen sino enmascarar el comienzo de la infección [...] ni el stovarsol de Levaditi, ni los productos similares lanzados con fines de profilaxia por vía digestiva, han dejado de tener detractores, ni han logrado, en definitiva, arraigo en la práctica, $[\ldots]^{38}$.

La nueva profilaxis química oral que permitía la medicación autoadministrada con un mínimo de contacto con los dispensarios, las nuevas formulaciones de salvarsán oral, quedaban pues desacreditadas como la habían sido los métodos tópicos de profilaxis para la sífilis y la blenorragia.

La falta de apoyo médico a la estrategia de difusión de la profilaxis individual tanto física (preservativo) como química refleja tanto los miedos de la profesión médica a la pérdida de su rol establecido como el miedo a evitar las naturales consecuencias de la promiscuidad. Posición que contrasta con la insistencia en la consideración de la abstención sexual como el mejor método de prevención individual, reafirmando el binomio: prevención= $=$ castidad $^{39}$. El hecho de difundir estos conocimientos entre la población general significaba reconocer y sancionar las prácticas sexuales ilegítimas, es más, para algunos médicos incluso estos conocimientos incitaban a la realización de estas prácticas en la medida en que se difundían técnicas para evitar lo que se consideraba justo castigo por la falta cometida. Además, apoyar estas técnicas dificultaba la

38 Ibid., pp. 71-75.

39 «... la única forma de prevención que se recomienda es la continencia sexual hasta el matrimonio, y evitar cualquier contacto sexual con «mujeres fáciles» ya que la más elemental prudencia imponía la abstención». LÓPEZ RODRÍGUEZ, J.L. (1926), Lo que debe saber...» (Vulgarización científica), s.l. Citado por FERNÁNDEZ FERNÁNDEZ, C.M. (1996), «Medicina y Moral: la lucha contra las enfermedades venéreas en A Coruña», Anuario Brigantino, 19, 195-204, p. 200. 
campaña de abstención sexual que, siguiendo las recomendaciones de la $2^{a}$ Conferencia Internacional para la profilaxis de la sifilis y demás enfermedades venéreas, se proponía como el mejor método para evitar el contagio. Sin embargo, en España, a mediados de los años treinta y dentro de los sectores médicos más implicados en la lucha antivenérea esta orientación empieza a ser cuestionada y considerada como un error ${ }^{40}$.

La difusión de conocimientos para la prevención individual estuvo limitada por las consideraciones sexuales y morales de la época. El posicionamiento más apoyado en la moral, firme defensor de la regeneración moral y de la abstención sexual como estrategia preventiva individual, se impuso así sobre las posiciones más seculares que se basaban en muchos casos en hallazgos científicos.

A partir de la inauguración del dispensario antivenéreo Azúa en 1924 y, sobre todo, desde la apertura en 1928 del dispensario Martínez Anido - ambos en Madrid-, se inician las actividades de propaganda antivenérea de manera organizada. En este dispensario y, bajo la dirección de Julio Bravo, se centralizaron todos los asuntos referentes a la propaganda de la lucha antivenérea ${ }^{41}$. Para 1929 , la oficina había editado y repartido 18.000 carteles y había realizado una exposición con carteles de otros países. Los carteles, repartidos al menos desde 1927, planteaban los peligros para el varón que se ocultaban tras las relaciones con prostitutas o mujeres de «conducta ligera». Pero, además, otras temáticas fueron ocupando su espacio dentro de los carteles de propaganda antivenérea: la responsabilidad del hombre y la obligación de cuidar de la familia, la sociedad y la raza. El autocontrol, las diversiones puras y honestas y la educación física eran las bases en las que descansaba la abstención sexual. Los carteles insistían en la cuestión del autocontrol y de la abstención sexual del varón, nuevos valores que rompían la doble moral sexual que permitía una moral sexual diferente para cada sexo: «El cerebro y el corazón del hombre han de ser dominadores y no dominados, y es por tanto preciso explotar en los hombres de mañana su vanidad de tales, enseñándoles el verdadero concepto de masculinidad, que consiste en triunfar valientemente de los instin$t o s\rangle^{42}$. Se planteaba, pues, un cambio que introdujera tanto la idea de la capacidad que tenía el varón para controlar y refrenar sus impulsos sexuales como la idea de la abstinencia sexual como fuente de salud.

40 Bertoloty, R. (1934), «Un aspecto de la lucha antivenérea: el problema de la profilaxis social de la gonorrea», Actas Dermo-Sifiliográficas, 27, 179-183.

41 Comité EjeCutivo ANTIVENEREO (1928), p. 62.

42 Fernandez DE LA PORTILla (1934), p. 108. 
En última instancia, la propaganda antivenérea se articulaba, por una parte, sobre la idea del peligro que suponía para el varón las relaciones con el mundo de la prostitución clandestina o de las mujeres de «conducta ligera» $\mathrm{y}$, por otra, sobre las nuevas concepciones de la masculinidad que, basadas en el autocontrol y en la responsabilidad, se estaban difundiendo.

Estos nuevos valores masculinos, que los abolicionistas defendían ardientemente, recibían el apoyo de los sectores feministas. Igualmente los dermatovenereólogos entendían que las mujeres debían participar en la lucha antivenérea tanto como madres como futuras esposas ${ }^{43}$.

$\mathrm{Al}$ igual que en otras de las más importantes campañas médico-sociales de la época, las campañas contra la tuberculosis y contra la mortalidad infantil, la campaña antivenérea empleó un nuevo espacio médico, llámese consultorio, dispensario o centro de higiene, que se introdujo en el tejido urbano con una agresividad desconocida y perdurable. Desde este espacio médico, la educación se convirtió en arma decisiva para la extensión de las prácticas higiénicas, para el cambio de los comportamientos populares ${ }^{44}$.

Una parte importante de la propaganda antivenérea así como la acción de vigilancia y control de enfermeras visitadoras e instructoras sociales se realizará desde el dispensario antivenéreo. Igualmente, los dispensarios eran espacios para la educación en higiene sexual, para la educación sexual antivenérea:

«El verdadero núcleo de la acción social contra el peligro venéreo, en las clases proletarias y populares, es el dispensario antivenéreo [... ] Debe ser, por tanto, el Dispensario centro de diagnóstico, de previsión, de tratamiento, de educación, y de asistencia, en el cual la acción mancomunada de la ciencia para curar, el Estado para legislar y sufragar y la acción social, por la educación higiénica, completarán la obra de redención humana que consiste en librarse de estas enfermedades tan destructoras para ti, para ella y para vuestra prole. Para nosotros, el primordial interés del Dispensario consiste en la difusión de doctrinas de educación higiénica» ${ }^{45}$.

Los médicos higienistas y los clínicos venereólogos, no solo entendieron el dispensario como espacio físico para la educación sexual antivenérea sino como faro del que irradiaba esta educación a la sociedad. Las Juntas Provin-

43 NAVARRo FernandeZ (1931), pp. 165-167.

44 Rodriguez Ocaña, E. y Molero Mesa, J. (1993), «La cruzada por la salud. Las campañas sanitarias del primer tercio del siglo XX en la construcción de la cultura de la salud», en: MonTIEL, L. (coord.), La salud en el estado del bienestar. Análisis histórico, Madrid, Editorial Complutense, pp. 133-48.

45 NAVARRO FERNANDEZ (1931), p. 126. 
ciales de Sanidad publicaban cartillas, folletos y material de propaganda que escribían médicos de los dispensarios y éstos se entregaron a una campaña de conferencias y mítines ${ }^{46,47}$, en los que la presencia de la mujer era importante ${ }^{48}$. En estos escritos y conferencias se pueden observar los contenidos de esta educación sexual antivenérea que iba dirigida a hombres y mujeres. Para los hombres, el contenido fundamental es alertar sobre los peligros inherentes al sexo y sobre los peligros que suponía mantener relaciones sexuales ilícitas. Para las mujeres los contenidos se centran en su papel como madres y esposas.

La definición, pues, de los roles sexuales y la regeneración moral se percibía como parte del funcionamiento de los dispensarios antivenéreos: "Esta obra de propaganda y de educación social ha de permitir que, sin desdoro

46 LOPEZ MARTINEZ, J. (1930), Los males venéreos en niñeras y nodrizas y mujer embarazada (Vulgarizaciones cientificas), La Coruña, Publicaciones de la Junta Provincial de Sanidad de La Coruña. «La intervención de la mujer (madre, esposa y maestra) en la Lucha antivenérea», conferencia celebrada en la Reunión Recreativa e Instructiva de Artesanos de la Coruña en 1928. Citado por FernandeZ FERNANDEZ (1996), p. 198.

47 Mención aparte merece la propaganda sanitaria llevada a cabo por el médico Navarro Fernández en Madrid: «Merced a nuestros esfuerzos y a los diez años consecutivos de mítines dominicales, y a las múltiples conferencias en gran escala, a los soldados y a los marineros, en el Real Cinema y Argüelles, y al público en general en todos los demás teatros, y la difusión de nuestra gran revista Higiene Social, han dado el resultado apetecido». (Más de 500 conferencias y pasando de los 300 mítines populares). NAVARRO FERNANDEZ (1931), p. 157-158. Esta afirmación de Navarro Fernández acerca de la eficacia y resultados de las conferencias y mítines populares ha de ser cuestionada a la luz de otros documentos. En una carta de Charles Bailey, el enviado de la Fundación Rockefeller en España, en 1925, sobre las sesiones públicas de propaganda sanitarias realizadas por Navarro y sus colegas se relata: «Estuve allí sentado durante tres horas escuchando a los cuatro primeros de los diez que iban a hacer uso de la palabra, cada uno de los cuales empleó la mayor parte de su tiempo en alabar al Dr. Navarro Fernández, a los que le habían precedido y a los que hablarían después, mientras que los temas objeto de su charla apenas fueron sino esbozados, sin que propusieran solución alguna o manera de enfrentarse a los problemas, de modo que no podía evitar pensar, como ya me habían advertido, que eran escasísimos sus frutos, salvo que los médicos conseguían mucha publicidad, que les reportaría muchos pacienteș.») Carta de Charles A. Bailey a Florence M. Read, 19-02-1925, Rockefeller Archives Center, Rockefeller Foundation Archives, Record Group 5, Series 1.2, Box 238, Fólder 3060. Agradezco a Esteban Rodríguez Ocaña la utilización de este documento y su apreciación crítica.

48 GonZÁlez CAStillejo, M.J. (1994), «Lo ‘Sagrado' y lo 'Profano'. Reflexiones sobre la moral social en la Segunda República, en: RAMOS, M.D. (coord.), Nuevas perspectivas sobre la Segunda República en Málaga, Málaga, Universidad de Málaga, pp. 115-130; p. 127. 
para nadie, pueda llegar la necesaria colaboración de las mujeres a tan interesante cruzada de misericordia, de fortaleza y de cultura [...] $\rangle^{49}$.

Los testimonios sugieren que la articulación de las enfermedades venéreas como un problema de salud pública en la España contemporánea ofreció una legitimación poderosa para la regulación y construcción social de las «sexualidades peligrosas». Las implicaciones del mundo privado de la sexualidad para la salud social y la eficiencia sancionaban nuevas formas de vigilancia y control. Los dispensarios antivenéreos formaban parte de la nueva higiene del dispensario en el cual los focos de preocupación y control en la salud pública se desplazaban de cuestiones de saneamiento y medio ambiente a modelos de contacto social y transmisión. Como ha señalado David Armstrong: «El camino de la enfermedad venérea a través de la comunidad trazaba los hilos que unían una persona íntimamente con otra» ${ }^{50}$.

El tratamiento y la propaganda fueron usados para articular esencialmente valores de las clases medias de moderación, auto-control, abstinencia e higiene como una manera de moralizar a las clases más pobres que acudían a las clínicas.

«Misioneros de tal doctrina han de ser los médicos encargados de los servicios oficiales antivenéreos, cuya actuación, repetimos, que no ha de concretarse al tratamiento de los enfermos que se les presenten, sino que debe comprender la enseñanza de tales enfermos en materia de profilaxis individual, ante nuevos riesgos personales y de profilaxis social, en cuanto al peligro que representan entre sus semejantes» ${ }^{51}$.

49 Fernandez de la Portilla (1934), p. 114.

50 Armstrong, D. (1983), Political Anatomy of the Body: Medical Knowledge in Britain in the Twentieth Century, Cambridge, p. 7-18.

51 FERnANDEZ DE LA PORTILla (1934), p. 102. 